\title{
The Effect of a Student Pharmacist Directed Health-Education Program for Elementary- School Children
}

Kelly L. Matson, PharmD, BCPPS ; Katherine K. Orr, PharmD, AE-C ${ }^{1}$; Caitlin Marino, PharmD ${ }^{2}$;

Lisa B. Cohen, PharmD, CDE, CDOE, CVDOE ${ }^{1}$

${ }^{1}$ Department of Pharmacy Practice, College of Pharmacy, The University of Rhode Island

${ }^{2}$ Department of Pharmacy, University of Rochester Medical Center

\begin{abstract}
Objective: The primary objective of this study was to measure the effect of an annual student pharmacist led elementary-school health education program by assessing children's comprehension of educational sessions. Secondary objectives were to evaluate student pharmacists' knowledge of health-related topics and practice skills.

Methods: Student pharmacists led interactive learning sessions for elementary school students on nutrition, physical activity, summer safety, hygiene, medication safety, and tobacco prevention. Pre-and post-intervention surveys were administered to measure change in knowledge of health promotion and healthy lifestyles. Student pharmacists also completed pre-and post-health education intervention surveys to measure change in self-perception of knowledge, confidence, and practice application of health-related topics and practice skills.

Results: Three-hundred and four elementary school children participated in the study with significant knowledge improvements observed in medication safety and tobacco prevention. Twenty-five student pharmacists completed surveys, resulting in a collective self-improvement in each area measured.

Conclusion: Interactive educational sessions led by student pharmacists have a positive impact on elementary school children's knowledge. Student pharmacists also demonstrated professional growth through increased knowledge, confidence, and communication skills in interacting with pediatric populations.

Practice Implication: A co-curricular educational activity allowed student pharmacists to promote health and wellness to elementary students, a Healthy People 2020 goal, while also providing an opportunity to develop professional skills for future practice with pediatric patients.
\end{abstract}

Keywords: community engagement, health education, pediatrics

\section{Background}

Healthy People 2020 established national objectives to promote health and wellness and prevent health problems in children through comprehensive health education within the school environment. ${ }^{1}$ Objectives of the Educational and Community-Based Programs (ECBP) advise comprehensive school health education to include tobacco use prevention, healthy diet, and physical activity for school-aged children. Additional ECBP recommend promotion of personal health and wellness, such as hand hygiene, sun safety and skin cancer prevention, as well as growth and development. Children in early childhood are typically healthy, however they are at risk for obesity, asthma, and other chronic conditions that may affect their health and well-being during adolescence and adulthood. Curricula within schools should encourage healthy eating behaviors, physical education, and other healthy habits including poison and tobacco prevention, hand hygiene and medication safety.

Corresponding Author: Kelly L. Matson, PharmD, BCPPS

Department of Pharmacy Practice

College of Pharmacy, The University of Rhode Island

7 Greenhouse Rd., Kingston, RI 02881

P: 401-874-5811; Email: matson@uri.edu
Most elementary schools provide nutrition education on diet and health in their curricula. ${ }^{2}$ Nonetheless, adequate nutrition and healthy meal choices remain a major concern in children and adolescents in the United States. Currently, $17.4 \%$ of U.S. children aged 6-11 years meet the definition of obese and $4.3 \%$ are considered extremely obese. Of children and adolescents aged 2-19 years, $31.8 \%$ are overweight or obese, and rates of obesity and extreme obesity in adolescents (i.e., 12-19 years) continue to increase. ${ }^{3}$ Elementary-school teacher-developed nutrition education materials may not always provide instruction that raises awareness of specific eating behaviors. Examples include soda consumption or the functionality of food labels for choosing healthy foods, although these educational tools have been sought to help curb obesity. ${ }^{2,4,5}$ Additionally, approximately one-third of elementary school (ES) children have daily physical education and less than onefifth have extracurricular physical activity programs at school. ${ }^{6}$ The Department of Education's Early Childhood Longitudinal Survey reported expanding physical education to 5 hours per week could reduce the incidence of overweight children by $4.2 \%{ }^{6} \quad$ Furthermore, knowledge of cardiovascular health through daily exercise recommendations and its relationship to a healthy heart should be included within physical education. ${ }^{7}$ Through knowledge, students have the ability to understand the importance of exercise to help promote 
healthy patterns of physical activity through childhood and into adulthood.

Health education in self-care, medication safety and common pediatric disease states often is not part of the school-based curricula in the United States. ${ }^{2}$ Families typically find this type of education through awareness campaigns from national organizations or their family provider. Although both resources are valuable, evidence shows these health education needs are not always being met. High rates of poisonings still exist with almost half $(46.4 \%)$ of US poisonings occurring in children 6 years of age and younger in $2016 .{ }^{8}$ The majority $(99.4 \%)$ are reported as unintentional, and $26.5 \%$ of exposures were due to prescription and over-the-counter medications. Primary-care pediatrician counseling of basic hygiene, self-care routines, chronic disease states and medications may be limited through time constraints on practitioners. ${ }^{9}$ This decreased time spent on health education with families is worrisome as more of pediatricians' time is spent in practice management and coordination care services given the increased prevalence of children with chronic diseases. In children with a chronic disease such as asthma, evidence has shown caregiver education and parental peercoaching methods provide positive clinical outcomes supporting the need for education. ${ }^{10,11}$ Alternative methods, such as school-based education, could provide a universal and unique approach for disseminating essential health information.

Broad-based ECBP goals of Healthy People 2020 are to establish evidence-based health and education interventions, to determine their impact and effectiveness, and to increase the number and skill-level of health workers in the community to support healthier communities. ${ }^{1}$ Co-curricular activities within a health professional curriculum provide an opportunity to achieve both Healthy People 2020 ECBP goals, as well as national objectives of increasing inclusion of core clinical prevention and population health content in student healthcare, specifically PharmD, education. Co-curricular activities would allow student learning and assessment, and additionally provide educational and community-based programs by student pharmacists (SP) in training. Health education for children delivered by healthcare professional students is an innovative practice. ${ }^{12-17}$ Through partnership with local schools, health-education programs can enhance SP' perspectives regarding importance of service, stimulate their understanding of health-related topics, and enhance their communication skills.

The primary objective of this study was to measure the effectiveness of an annual health fair for ES children led and delivered by SP by assessing the children's comprehension of the educational sessions. Secondary objectives were to evaluate student pharmacists' self-perception of knowledge and confidence in health-related topics and practice skills while participating in a pediatric co-curricular experience.

\section{Experimental Design and Methods}

The ES partner for the educational intervention was a Title 1 school with yearly enrollment of over 300 students in Kindergarten through grade 4 . Program activities for the academic years, 2012-2013 and 2013-2014, were determined in conjunction with the school nurse, physical education teacher, and university faculty. Activities are listed in Table 1. Written parental permission and assent for each participating ES student was obtained prior to study participation. An assessment of ES students' performance was evaluated by preand post-health education intervention quizzes, addressing students' knowledge of health promotion and healthy lifestyles by way of true/false, and "I don't know" statements. Age appropriate quizzes for the ES students were developed by the pediatric and self-care faculty members and distributed by ES teachers with instructions for anonymous administration. A total of 6 questions was posed to Kindergarten and grades 1-2 students, including nutrition, hygiene, physical activity and medication safety. Grade 1-2 students had additional questions regarding asthma or summer safety depending on the predetermined program activities for that academic year. Grade 3-4 students were posed 8 questions, including nutrition, hygiene, physical activity, medication or summer safety, and tobacco prevention. Pre-quizzes were given approximately 1 month prior to the health fair, and post-quizzes were administered during a physical education course approximately 1-2 weeks following the health fair.

Student pharmacists were either enrolled in the pediatric pharmacotherapy elective course (professional year 3 ) or recruited to participate based on advanced pharmacy practice experience (professional year 4), including pediatrics, community, or outreach settings. Student pharmacists in the pediatric elective received a one-hour lecture and case-based activities on pediatric communication skills to provide basis to develop and deliver age-appropriate materials. Advanced pharmacy practice students received faculty advisement on pediatric communication skills. The project was for course credit for all SP. Additionally, pediatric SP were required to write a reflection on the relationship of knowledge and skills on professional growth, or the role of the pharmacist in community outreach and its fostering of civic responsibility in the profession. Student pharmacists, working in pairs, selected program activities (Table 1) and developed a tenminute educational session with subsequent 10-15-minute hands-on activity for each topic. Program activities were delivered by SP in continuous 30-minute periods to small groups of ES students during a 3-hour annual health fair. Student pharmacists delivered a total of 6 identical educational sessions and activities for complete coverage of each ES grade level. Student pharmacists were evaluated by pre- and post-health education intervention surveys for knowledge and confidence of practical application of healthrelated topics, health and wellness promotion strategies, communication skills, and perceptions of civic responsibility 
(Appendix A). Pre-surveys were administered approximately 1 month prior to the day of the health fair when project was first assigned, and post-surveys were administered immediately after the health fair. Survey data for SP were matched and remained confidential. The project was approved by The University of Rhode Island Institutional Review Board. All statistical analysis was completed with IBM SPSS statistics for Mac, version 24. Chi-square tests were used to compare the changes in ES-students' knowledge of health-related topics. Descriptive statistics were used to determine SP demographics, and paired t-tests were used to determine changes in knowledge and confidence in practical application.

\section{Results}

Student pharmacists provided a youth-oriented, healtheducation program to ES students during two consecutive academic years, of which 304 ES students completed the preand post-knowledge assessment. Reported changes from baseline knowledge in ES children is in Table 2. Elementary school students had positive improvement in knowledge for all health-related topics, however, not all were statistically significant. Significant improvements in knowledge were observed in Kindergarten students for medication safety (i.e., medication versus candy) $(p<0.001)$, and in grade 3 and 4 students for tobacco prevention (i.e., smoking can cause lung damage) ( $p=0.007)$. Grade 1 and 2 students had knowledge improvement regarding the benefit of increased hydration compared to the limitations of cough and cold products when ill with a cough $(p=0.015)$.

Twenty-five SP completed the matched surveys; all but one student provided demographic information (Table 3). Collective pediatric self-care knowledge and confidence in its practical application based on program activities improved by $12.7 \pm 5.2 \%$ and $7.5 \pm 2.3 \%$, respectively in SP. Improvements in knowledge of health promotion strategies, communication, and the role of the pharmacist in childhood health education increased 20.4\%, 15.7\%, and 1.8\%, respectively (Figure 1). Practical application also improved $10.7 \%, 8.9 \%$, and $5.4 \%$ in the same areas of interest (Figure 2).

\section{Discussion}

School-based, comprehensive health curriculum to promote health and wellness in children is recommended by Healthy People 2020. ${ }^{1}$ A student pharmacist-led health fair supported the goals of Healthy People 2020 by providing educational interventions to ES students in a variety of healthcare topics. Elementary school students' knowledge improved among all health-related topics presented, however, the study observed only significant improvements in ES children's comprehension of medication safety (i.e., medication versus candy), over-thecounter cough and cold product use, and a specific complication of smoking.

Increased understanding in medication safety and appropriate use of cough and cold products in ES students are additional steps towards improving proper medication use in children. A previous study observed perceived benefit of SP educating children about over-the-counter medications and medications safety. ${ }^{18}$ However, this study only surveyed adult participants, including SP, faculty preceptors, ES teachers and administrators regarding the importance of medication safety education. Limited use of cough and cold products in children has been recommended based on lack of efficacy and potential adverse effects. ${ }^{19,20}$ Providing education to ES students for their better understanding regarding these recommendations and medication safety may help close the gap in proper use of over-the-counter medications in children.

Drug Abuse Resistance Education (DARE), an educational program for substance use prevention, including tobacco, alcohol and illegal drugs had previously been implemented into schools nationwide and federally funded for school-aged youth. ${ }^{21}$ Evidence suggests the DARE program has had a slight impact on increasing adolescents' knowledge of tobacco use risks and overall smoking rates. ${ }^{22}$ We similarly assessed children's knowledge of smoking risks and consequences, and our results also found increased knowledge in smoking risks with anticipation the education would translate into lower rates of use in the future for the children studied. A recent study using SP to educate ES students similarly observed an increase in short-term knowledge from baseline regarding tobacco use. ${ }^{23}$ Our findings correspond with Ostroff, et. al. that SP are a viable resource to provide tobacco prevention education to ES schools.

Limitations of the study include the possibility of recall bias among ES students. True/false/I don't know questioning may have left room for potential skewing of the data due to guessing answers rather than answering based upon true knowledge of the subject or answering based upon what is currently done in the home. Surveys also were given shortly after health-education program sessions, determining shortterm recall only. The study did not assess long-term retention of the information, which may impact the true lasting benefit, nor did it assess long-term outcomes. The effect of the healtheducation program is only able to postulate a successful grasp of the information with the hope it will translate into future healthier choices and outcomes for the children studied. Additionally, our results may not be observed in a different population of children as other ES demographics and environment may not heed similar responses. As well, other SP educational sessions may not provide the same message or be delivered in the same manner, thus study results may not be repeated if replicated elsewhere. The promotion of schoolbased, health education provided by health professional students although does meet the basic components of Healthy People 2020.

Increasing the number and skills level of health professionals as promoters and educators of health and wellness is also a Healthy People 2020 goal. The ES health fair provided an 
opportunity for SP to promote strategies to improve health and wellness. Prior to engaging in this project, SP had a proficient foundation in health and wellness elements, though it was further enhanced upon completion of the health fair with a $20 \%$ improvement in knowledge and $10 \%$ increase in practical application of health promotion strategies. Furthermore, SP had improvements in their knowledge and application of pediatric communication skills, which is essential to pharmacy practice. However, both improvements noted in SP may not be replicated for other SP or healthcare professional students depending students' curricula and level of comfort in developing and delivering education.

This student-directed health education program provides an opportunity for SP to meet co-curricular standards included in the Center for the Advancement of Pharmacy Education (CAPE) 2013 Educational Outcomes. ${ }^{24}$ Several sub-domains may be achieved within this activity to augment learning outside the didactic classroom and experiential settings. Designing prevention and educational strategies to improve health and wellness (2.3), though not exclusively co-curricular in nature, are essential for pharmacy practice through providing foundational knowledge at the health fair. The elements of health and wellness also reinforce self-care content delivered earlier within the SP didactic curriculum. The role of the educator is met in providing an educational interactive program directed to school-aged children (3.2), especially the implementation of an interactive learning program that is age appropriate, demonstrating an understanding of one's audience and the ability to adjust material. Communicating effectively with a pediatric audience based upon developmental stage principles (3.6) is also an essential aspect in the development of SP. Self-awareness and professionalism may be achieved by reflecting upon one's knowledge and skills in relation to professional growth (4.1), as well as upon one's community outreach and role of the pharmacist on fostering civic responsibility (4.4).

A future direction for co-curricular opportunities associated with this activity is the introduction of an electronic portfolio system through the Sakai learning management platform currently utilized at the University of Rhode Island. It provides a standardized mechanism of capturing and documenting cocurricular activities through reflections, allowing for faculty feedback. A similar activity has been considered with middle school children, which would require changes in the communication approach and content areas, yet still meet many of the sub-domains described above. These activities would be available for students to participate in without having course credit attached, rather as a requirement for their co-curricular portfolios prior to starting advanced pharmacy practice experiences.
Conclusion

A health-education program directed by SP met the Healthy People 2020 goal of promoting health and wellness in ES children in a school environment. The program also increased the number, knowledge and practice application of childhood health and wellness strategies, and pediatric communication skills of pharmacy students to help support healthier communities in the future.

Funding: This work was supported by NACDS Million Hearts Grant and local educational grant through partner school

Conflicts of Interest: None

Treatment of Human Subjects: IRB review/approval required and obtained from The University of Rhode Island

\section{References}

1. U.S. Department of Health and Human Services. Educational and community-based programs. In: Healthy People 2020. Available at: http://www.healthypeople.gov/2020/topicsobjectives 2020/overview.aspx?topicid=11.

2. National Center for Education Statistics. Nutrition education is public elementary and secondary schools. Available at:

https://nces.ed.gov/surveys/frss/publications/96852/.

3. Ogden CL, Carroll MD, Lawman HG, et al. Trends in obesity prevalence among children and adolescents in the United States, 1988-1994 through 2013-2014. JAMA 2016; 315(21): 2292-9.

4. Centers for Disease Control and Prevention. Guidelines for school health programs to promote lifelong healthy eating. MMWR 1996; 45 (RR-9): 1-33.

5. Story M, Nanney MS, Schwartz MB. Schools and obesity prevention: creating school environments and policies to promote healthy eating and physical activity. Milbank Q 2009; 87(1): 71-100.

6. U.S. Department of Health and Human Services. Physical inactivity and sedentary behaviors. Available at: http://aspe.hhs.gov/health/reports/child obesity/.

7. Institute of Medicine. Chapter 5: Approaches to physical education in schools. In: Educating the student body: Taking physical activity and physical education to school. Washington, DC: The National Academies Press; 2013. Available at: https://www.nap.edu/read/18314/chapter/7.

8. Gummin DD, Mowry JB, Spyker DA, et al. 2016 annual report of the American association of poison control centers' national poison data system (NPDS): 34th annual report. Clin Toxicol (Phila) 2017; 55(10):10721254.

9. Basco WT, Rimsza ME, AAP Committee on Pediatric Workforce. Pediatrician workforce policy statement. Pediatrics 2013; 132(2): 390-7. 
10. Yin HS, Gupta RS, Tomopoulos S, et al. A low-literacy asthma action plan to improve provider asthma counseling: a randomized study. Pediatrics 2016; 137(1): e2015046.

11. Garbutt JM, Yan Y, Highstein G, et al. Cluster randomized trial shows telephone peer-coaching for parents reduces children's asthma morbidity. J Allergy Clin Immunol 2015; 135(5): 1163-1170.e1-2.

12. Johnson JF. A diabetes camp as the service-learning capstone experience in a diabetes concentration. Am J Pharm Educ 2007; 71(6): 119.

13. Begley K, Haddad AR, Christensen C, et al. A health education programs for underserved community youth led by health professions students. Am J Pharm Educ 2009; 73(6): 98.

14. McConnell E, Clasen C, Stolfi A, et al. Community service and the pediatric exam: an introduction to clinical medicine via a partnership between first year medical students and a community elementary school. Teach Learn Med 2010; 22(3): 187-90.

15. Laughlin A, Pothoff $M$, Schwartz $M$, et al. Combining service learning and research: partnering with schools. Nurse Educ 2010; 35(5): 188-191.

16. Vogt MA, Chavez R, Schaffner B. Baccalaureate nursing student experiences at a camp for children with diabetes: the impact of a service-learning model. Pediatr Nurs 2011; 37(2): 69-73.

17. Falter RA, Pignotti-Dumas K, Popish SJ, et al. A service learning program in providing nutrition education to children. Am J Pharm Educ 2011; 75(5): 85.
18. Abraham O, Feathers A, Mook $\mathrm{H}$, et al. The perceived benefits of student pharmacists educating children about over-the-counter medication safety. Curr Pharm Teach Learn 2019; 11(2): 184-191.

19. Malesker MA, Callahan-Lyon P, Ireland B, et al. Pharmacologic and nonpharmacologic treatment for acute cough associated with the common cold: CHEST expert panel report. Chest 2017; 152(5): 1021-1037.

20. Lowry JA, Leeder JS. Over-the-counter medications: update on cough and cold preparations. Pediatr Rev 2015; 36(7): 286-97.

21. West SL, O'Neal KK. Project D.A.R.E. outcome effectiveness revisited. Am J Public Health 2004; 94(6): 1027-1029.

22. Ahmed NU, Ahmed NS, Bennett CR, et al. Impact of a drug abuse resistance education (D.A.R.E) program in preventing the initiation of cigarette smoking in fifthand sixth-grade students. J Natl Med Assoc 2002; 94(4): 249-256.

23. Ostroff JL, Wolff ML, Andros C, et al. Student pharmacists provide tobacco use prevention education to elementary school children: a pilot experience. Curr Pharm Teach Learn 2017; 9(5): 869-873.

24. Medina MS, Plaza CM, Stowe CD, et al. Center for the Advancement of Pharmacy Education 2013 Educational Outcomes. Am J Pharm Educ 2013; 77(8): 162. 
Table 1. Health-Education Program Activities

\begin{tabular}{|l|l|}
\hline Exercise & $\begin{array}{l}\text { Just Dance } 3 \text { video for Wii } \\
\text { Clever Ball/Parachute Play }\end{array}$ \\
\hline Medication Safety & $\begin{array}{l}\text { Poison prevention } \\
\text { Cough and cold products } \\
\text { Acute otitis media treatment (over-the-counter medications and antibiotics) }\end{array}$ \\
\hline Tobacco Prevention & Cigarette ingredients and smoking complications \\
\hline Hygiene & $\begin{array}{l}\text { Cough and sneezing etiquette; germ overview } \\
\text { Proper hand washing }\end{array}$ \\
\hline Nutrition & $\begin{array}{l}\text { MyPlate information sheets and poster } \\
\text { Food group match game } \\
\text { Comparing products for sugar amounts } \\
\text { Food labels/calorie counting }\end{array}$ \\
\hline Summer Safety & $\begin{array}{l}\text { Tick prevention and hiking safety } \\
\text { Sun protection and beach safety } \\
\text { Bike safety }\end{array}$ \\
\hline Asthma/Allergy & \begin{tabular}{l} 
Asthma trigger game and clinical manifestations \\
\hline
\end{tabular} \\
\hline
\end{tabular}


Table 2: Change in Knowledge of Health-Related Topics in Elementary-School Children

\begin{tabular}{|c|c|c|c|}
\hline & $\begin{array}{l}\text { Correct Answer } \\
\text { Baseline (\%) }\end{array}$ & $\begin{array}{c}\text { Correct } \\
\text { Answer Follow } \\
\text { Up (\%) }\end{array}$ & $\begin{array}{c}\text { P-value } \\
\left(X^{2}\right)\end{array}$ \\
\hline \multicolumn{4}{|l|}{ Nutrition } \\
\hline My Plate (Fruits and Vegetables) $)^{1,2,3}$ & 87.9 & 92.8 & 0.311 \\
\hline Food groups (Healthy Grain) ${ }^{1}$ & 85.7 & 90.0 & 1.00 \\
\hline Sugar amounts (Soda or Pop) ${ }^{2}$ & 73.9 & 86.4 & 0.123 \\
\hline Food labels/calorie counting (Servings per container) ${ }^{3}$ & 83.9 & 85.7 & 0.900 \\
\hline \multicolumn{4}{|l|}{ Physical Activity } \\
\hline Play or exercise for 60 minutes per day ${ }^{1(+), 2(+), 3}$ & 100 & 100 & 1.00 \\
\hline Dancing is kind of exercise ${ }^{1(*), 3(+)}$ & 85.7 & 100 & 1.00 \\
\hline Exercise helps the heart become stronger and larger ${ }^{3}$ & 97.5 & 100 & 0.820 \\
\hline \multicolumn{4}{|l|}{ Hygiene } \\
\hline $\begin{array}{l}\text { Washing hands (Happy Birthday song } 2 \\
\text { times/Germs) }\end{array}$ & 83.6 & 88.1 & 0.354 \\
\hline Cough and sneeze etiquette ${ }^{1}$ & 47.2 & 85.7 & 0.062 \\
\hline Do not place fingers in mouth and nose ${ }^{1}$ & 68.8 & 88.9 & 0.228 \\
\hline \multicolumn{4}{|l|}{ Medication Safety and Poison Prevention } \\
\hline Poison is harmful to the body ${ }^{1}$ & 60.0 & 85.7 & 0.310 \\
\hline Cleaning supplies location ${ }^{1}$ & 50 & 50 & 1.00 \\
\hline Medication/Candy (Look alike) ${ }^{1}$ & 0 & 95.7 & $<0.001$ \\
\hline Parental permission for medication ${ }^{2}$ & 96.3 & 96.3 & 1.00 \\
\hline Cough and cold products ${ }^{2(+)}$ & 22.2 & 73.3 & 0.015 \\
\hline $\begin{array}{l}\text { Acute otitis media treatment }{ }^{2(*)} \\
\text { (Over-the-counter vs. prescription medications) }\end{array}$ & 39.1 & 50.0 & 0.454 \\
\hline \multicolumn{4}{|l|}{ Summer Safety } \\
\hline Sunscreen and sun protection ${ }^{2(+)}$ & 100 & 100 & 1.00 \\
\hline Tick prevention ${ }^{3(*)}$ & 97.0 & 100 & 0.860 \\
\hline \multicolumn{4}{|l|}{ Asthma/Allergy } \\
\hline Allergies may make asthma symptoms worse ${ }^{2(*)}$ & 93.6 & 100 & 0.711 \\
\hline Asthma exacerbation makes breathing harder ${ }^{2(*)}$ & 97.3 & 100 & 0.773 \\
\hline \multicolumn{4}{|l|}{ Tobacco Prevention } \\
\hline Smoking can cause cough and yellowing of teeth ${ }^{3}$ & 91.1 & 100 & 0.754 \\
\hline Smoking can cause lung damage ${ }^{3}$ & 66.7 & 94.7 & 0.007 \\
\hline
\end{tabular}

* 2012-2013 only

+ 2013-2014 only

1. Kindergarten

2. First and second grade

3. Third and fourth grade 
Table 3: Demographics of Pharmacy Students

\begin{tabular}{|c|l|}
\hline & $\mathrm{N}=24$ \\
\hline $\begin{array}{c}\text { Professional Year } \\
\text { P3 }\end{array}$ & $3(12 \%)$ \\
P4 & $21(88 \%)$ \\
\hline Mean Age (Range) & $23.5(22-26)$ years \\
\hline Gender Female & $20(83 \%)$ \\
Male & $4(17 \%)$ \\
\hline Work Experience & \\
Hospital & $7(29 \%)$ \\
Community & $16(67 \%)$ \\
Long-Term Care & $1(4 \%)$ \\
\hline Future Practice Area & \\
Cospital & $6(25 \%)$ \\
Community & $11(46 \%)$ \\
Other & $5(21 \%)$ \\
& $2(8 \%)$ \\
\hline
\end{tabular}



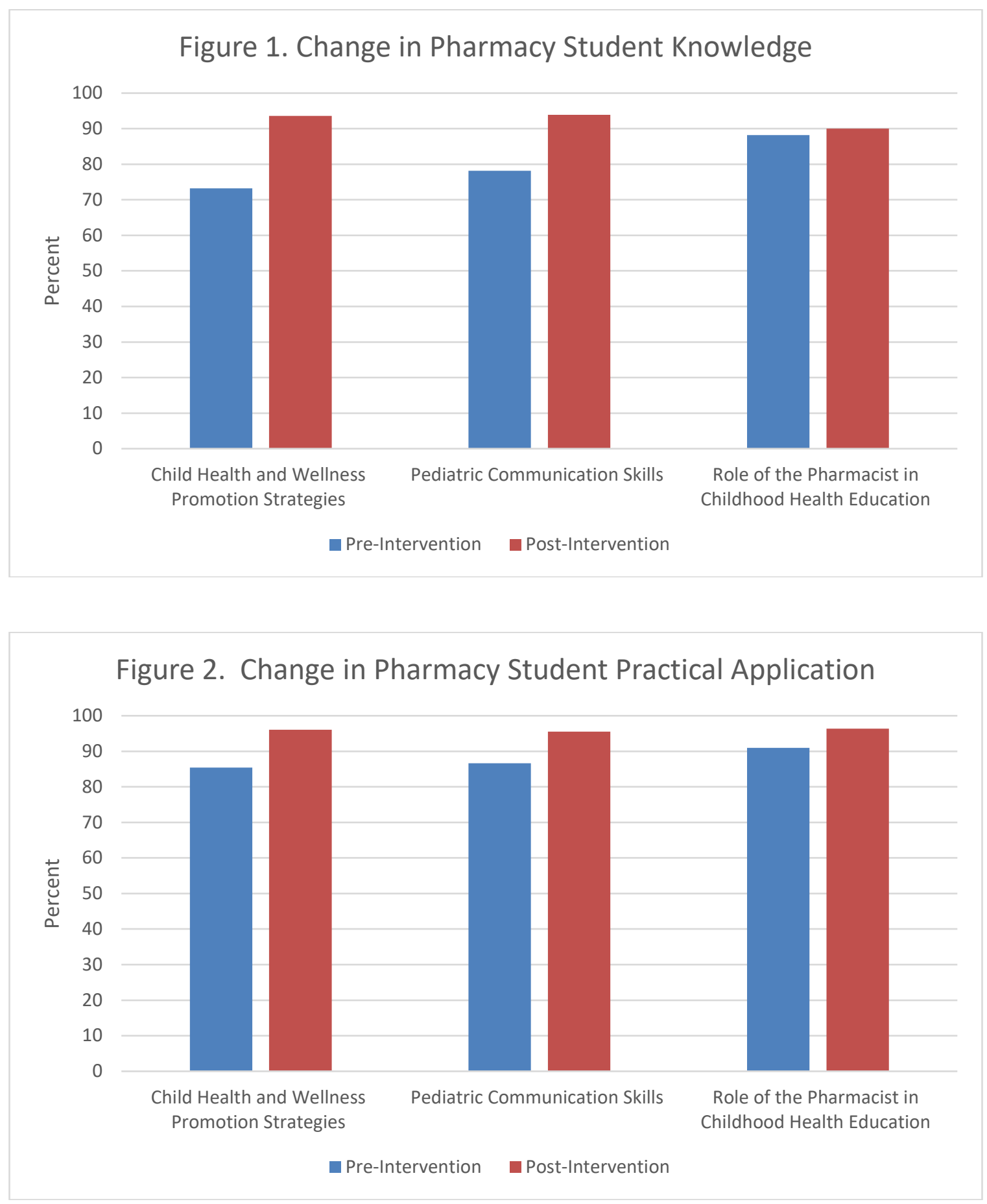


\section{Appendix A: Pharmacy Student Health Education Intervention Survey}

Please create your own participant ID. This code will only be used to match your pre and post-survey responses.

Participant ID: (month of birth / first 3 letters of mother's maiden name)

Please indicate your degree of agreement with each statement using a scale between 0 and $100 \%$ and record this in each box under each of the 3 columns. If you feel that the specific issue is not relevant, please use NA (not applicable).

\begin{tabular}{|c|c|c|c|}
\hline & I know & $\begin{array}{l}\text { To improve my } \\
\text { practice, } \\
\text { I value learning } \\
\text { about this: }\end{array}$ & $\begin{array}{l}\text { I am confident that I } \\
\text { can apply } \\
\text { knowledge about } \\
\text { this in my practice }\end{array}$ \\
\hline & $\begin{array}{l}\text { Please use a } \\
\text { scale of } 0 \text { to } \\
100 \% \text {, or NA }\end{array}$ & $\begin{array}{c}\text { Please use a scale } \\
\text { of } 0 \text { to } 100 \% \\
\text { or NA }\end{array}$ & $\begin{array}{c}\text { Please use a scale of } \\
0 \text { to } 100 \% \\
\text { or NA }\end{array}$ \\
\hline \multicolumn{4}{|l|}{$\begin{array}{l}\text { 1. Health promotion strategies to } \\
\text { improve children's well being }\end{array}$} \\
\hline \multicolumn{4}{|l|}{$\begin{array}{l}\text { 2. How to communicate healthcare } \\
\text { knowledge to a child }\end{array}$} \\
\hline \multicolumn{4}{|l|}{ 3. Medication safety for children } \\
\hline \multicolumn{4}{|l|}{$\begin{array}{l}\text { 4. Summer safety (i.e., Lyme } \\
\text { disease prevention and sun } \\
\text { protection) for children }\end{array}$} \\
\hline \multicolumn{4}{|l|}{ 5. Smoking prevention for children } \\
\hline \multicolumn{4}{|l|}{ 6. Poison prevention for children } \\
\hline \multicolumn{4}{|l|}{$\begin{array}{l}\text { 7. Asthma inhaler techniques in } \\
\text { children }\end{array}$} \\
\hline \multicolumn{4}{|l|}{ 8. Childhood asthma education } \\
\hline \multicolumn{4}{|l|}{ 9. Childhood diabetes education } \\
\hline \multicolumn{4}{|l|}{ 10. Childhood nutrition education } \\
\hline \multicolumn{4}{|l|}{$\begin{array}{l}\text { 11. Pedometer use in monitoring } \\
\text { physical activity }\end{array}$} \\
\hline \multicolumn{4}{|l|}{$\begin{array}{l}\text { 12. Hand hygiene importance in well- } \\
\text { being of children }\end{array}$} \\
\hline \multicolumn{4}{|l|}{$\begin{array}{l}\text { 13. The importance of the } \\
\text { pharmacist's role in childhood } \\
\text { health education }\end{array}$} \\
\hline $\begin{array}{l}\text { 14. Pharmacists-delivered community } \\
\text { outreach activities }\end{array}$ & & & \\
\hline
\end{tabular}

15. In my work with the WKES Health Fair, I intend to implement at least one practice or communication skill learned as a result of this project.
YES
NO
DOES NOT APPLY 
16. Your level of education:
a. Freshman
b. Sophomore
c. Professional Pharmacy Year 1
d. Professional Pharmacy Year 2

e. Professional Pharmacy Year 3

f. Professional Pharmacy Year 4

g. Other (specify):

17. Your gender:
a. Male
b. Female

18. Your age:
a. 18 years old
e. 22 years old
b. 19 years old
f. 23 years old
c. 20 years old
g. 24 years old
d. 21 years old
h. Other (specify):

19. Which choice best describes your pharmacy work experience?
a. Community
e. Nursing home
b. Hospital
f. Managed care
c. Ambulatory care
g. Industry
d. Home health care
h. Other (specify):

20. Which choice best describes your practice interest for the future?
a. Community
h. Clinical
b. Hospital
i. Compounding
c. Ambulatory care
j. Academia
d. Home health care
k. Informatics
e. Nursing home consultant
l. Veterinary
f. Managed care
g. Industry
m. Nuclear
n. Other (specify): 